\title{
Systematic Reviews and Meta-Analyses
}

\section{Parenting functioning in stunting management: A concept analysis}

\author{
Anggie Pradana Putri, ${ }^{1,2}$ Jin-Ru Rong ${ }^{1}$ \\ ${ }^{1}$ International Nursing PhD Program, National Taipei University of Nursing and Health Sciences, Taipei, \\ Taiwan; ${ }^{2}$ STIKES Mamba'ul 'Ulum Surakarta, Surakarta, Indonesia
}

\begin{abstract}
Stunting, a global issue, is the retarded growth and development of children resulting from inadequate nutrition, frequent infection, and insufficient psychosocial stimulation. It is usually an indicator of poor parenting. The role of parents is important for children's growth, development and learning. Parenting functioning is a concept health care professionals use to describe parenting activities for the purpose of intervention. But, the health professionals and patients have different understanding on parental functioning. There is a need to have a consistent definition of parenting functioning, and therefore this study aims to analyze the concept. Walker and Avant's method of concept analysis was used to study parenting functioning for the purpose of improving management of stunting. The attributes of parenting functioning are knowledge, competency, effort, responsibility, partnership, caring, teaching and communicating. Antecedents for parenting functioning are relationship, children's characteristics, careful observation and vicarious experiences. The consequences are positive child-rearing practice, less psychological stress and children's wellness. The empirical referents for parenting functioning are Keys to Interactive Parenting Scale (KIPS) and Parenting Interaction with Children: Checklist of Observations Linked to Outcomes (PICCOLO). In conclusion, this analytical concept can provide insights into nursing and public health colleagues to improve understanding of parenting functioning and to facilitate development of instrument to improve to an advance stage and to improve the stunting management.
\end{abstract}

\section{Introduction}

Stunting is a global problem faced by every country ${ }^{1}$ and generally indicates poor parenting functioning. ${ }^{2}$ Stunting, or chronic malnutrition, is the result of poor nutrition and health in early childhood, beginning in the womb. Stunt children do not grow to a proper height according to their age. The impairment also affects the brain in such a way that their cognitive potential may not be realized. Furthermore, it has a lifelong effect on children and may result to poor physical development and learning capacity, increased risk of infections and chronic diseases in adulthood, increased morbidity and mortality, as well as reduced productivity and economic well-being and may continue generation after gen- eration when not addressed. ${ }^{3}$

Many children are prone to be stunted after the age of six months, but it is difficult to identify with certainty before the age of two, and predicting the likelihood of stunting creates the possibility of intervention. Several factors associated with it are described in the 2014 WHO Conceptual Framework on Childhood Stunting. The most crucial are household and family factors, making children 3.22 times more likely to experience stunting, followed by inadequate complementary feeding. ${ }^{4}$ Lack of knowledge and information from parents often leads to poor feeding practices. These includes the inability to provide a diverse diet appropriate to the child's age, provision of solid early and irregular meals. ${ }^{5}$

The functioning of the parents is important for the growth and development of the children as well as for their knowledge. Efforts to deal with stunts in children should be focused on parents' nutritional knowledge. Parents may struggle to provide a good physical and social home environment for their children. ${ }^{2}$

The term parenting functioning originated from multidisciplinary nursing research that revealed ways that parents powerfully influence the physical and psychological growth of their children. The number of research reports on risk factors for stunting and measures to reduce stunting is increasing. Although professionals and policy makers have been studying parenting, current key concepts involving the role of parental functioning in child growth may be missing. ${ }^{6}$ Moreover, in Indonesia, health professionals and patients may understand parental functioning differently, but there is a need to have the same definition on the concept of parenting functioning.

Health care professionals use the concept of parenting functioning observe parenting activities and devise interventions. Concept analysis is a valuable strategy for developing models when a concept has been introduced in the literature but needs to be further defined or clarified. ${ }^{7}$ Concepts are the basic building blocks for constructing theories. ${ }^{8}$ Concept analysis can help identify the essential attributes of parenting functioning. These attributes may hold the key to the possible management of stunting. Public health and nurses need to explore the phenomenon in order to stimulate study that can help further in the development of the concept. Therefore, analysis of parental functioning hopefully will strengthen the concept for application in specific fields such as child health, social work, and policy-making.

Significance for public health

There are various approaches to manage stunting cases in Indonesia. Many excellent programs established by the Indonesian government have limited focus on parenting and intervention. Evidence show that parents have significant role in children's growth and development. Concept analysis of parenting functioning enables new insight for reaching a consensus, in order to promote management of stunting cases and to reduce their number in Indonesia. 


\section{Design and Methods}

To show how the concept of parenting functioning is defined in the literature, Walker and Avant's eight steps of concept analysis were used to organize the framework for this study. ${ }^{7}$ Concept analysis method consists of: i) choosing a concept, ii) specifying the purpose of the analysis, iii) identifying how the concept has been used, iv) defining unique characteristics of the concept, v) identifying model case(s), vi) identifying additional cases (borderline, related, contrary, invented and legitimate), vii) identifying antecedents and concequences, viii) defining ways of measuring the phenomenon.

According to Walker and Avant (2019), concept analysis must be focused and precise, but the end product is always evolving, because what seems true today is not guaranteed to seem true tomorrow. This suggest that as much as identifying with a concept can away valuable information from readers about a concept. Moreover, it can limit the usefulness of the outcome of the concept. ${ }^{7}$ Information on parenting functioning was searched from four different sources, such as online database (PubMed, CINAHL (Cummulative Index for Nursing and Allied Health) Plus with Full Text, Chochrane Library, Google Scholar), journal articles, dictionaries and official health website (both government and nongovernment). The search terms included parenting, "parenting functioning", stunting and "stunting management."

\section{Results and Discussion}

Parenthood comes from the Latin word "parere" which means to "bring forth, develop or educate". ${ }^{9}$ Parenting may then be understood as the raising of children and all the responsibilities and activities that involves. ${ }^{10}$ It is a multifaceted activity that includes many specific behaviors of parents that influence child development and can potentially prevent health problems among children and adolescents. ${ }^{11}$ Parenting functioning refers to all the activities and responsibilities involved in raising children that influence child outcomes. Parenting functioning points to ideals of parenting aimed at producing positive outcomes for children. ${ }^{12}$

The World Health Organization and United Nation Population Fund promotes attention to the idea that parental functioning is related to stunting of children based on research findings from community settings..$^{1,3}$ Another use of the concept is that parenting functioning is important for managing chronic conditions, according to Luyten et al. ${ }^{12}$ Early intervention can potentially prevent developmental disabilities and chronic conditions that require multidisciplinary health care services (e.g., pediatricians, psychologists, speech and language pathologists, and physical and occupational therapists, special educators). ${ }^{13}$

The concept of parenting functioning has been used successfully to resolve chronic pain, as described by (source). This case study of an adolescent with cancer suffering from chronic pain contributed the important insight that parental functioning and behavior can affect the experience of physical pain in adolescents. ${ }^{14}$ The concept has not only been applied in the area of chronic conditions. Parenting functioning also plays a role in helping children with special conditions. For example, improved parental functioning could enhance the effectiveness of treatment for children with Attention Deficit Hyperactivity Disorder. ${ }^{15}$

\section{Attributes}

Attributes are defining characteristics of a concept. ${ }^{8}$ Below are attributes of the concept of parenting functioning: The analysis tries to show groups of attributes that are those most commonly associated with this concept. Knowledge is the fact or knowing something about familiarity gained through experience. The knowledge needed by parents includes a milestone about the growth and development of children, child simulation and activity, appropriate nutrition, hygiene and adequate sanitation. ${ }^{16}$ Parents that have knowledge can get the meaning of the items of knowledge, and parents with a deep knowledge about a subject matter tends to have nuanced views, and they also tend to underestimate their expertise in parenting. In many cases, they will be generous with their time when it comes to responding to basic question related to parenting. However, the only real way to know is by someone with a similar deep knowledge on the field of talking or observation.

It can be assumed that when parents are aware about the condition of their stunted child, they will be gain more information from the internet, books, pediatrician, nurses and other health care providers. They have sufficient knowledge about stunting. When the other people (colleague or others) asked about their child or stunted condition, parents can explain correctly as mentioned in the literature. The parent can also share the information to others about their knowledge. Well-informed parents are more likely to engage in positive parenting practices. By contrast, those with less knowledge have a greater tendency to engage in negative parenting behaviors. ${ }^{17}$

Competency is an important skill required to execute a job. ${ }^{18}$ It is defined by commitments, abilities, knowledge, and skills that make it possible for someone to act effectively in a given situation. The other view of the differences between competence and competency, where competence is about standards, skills, and measurement, while competency is about behavior, how the standards are achieved. ${ }^{19}$ The effort of parents to achieve the competency can be carried out through joining the parenting class, seminars or other activities that can influence the behavior of the parents. Trainings that focus on parenting are essential also for gaining competency. One can say that having corresponding certificate can prove competency. The component of competency in parenting correlates with parental self-efficacy. It is the belief that parenting tasks can be performed successfully. Increased quality of parent-child interactions are associated with high levels of parental self-efficacy, increased warmth and responsiveness from parents, and parental engagement with and monitoring of adolescents.

Effort is defined as the use of energy to do something, exertion or strenuous exertion. Parental effort refers to the cost of raising offspring. This means how parents allocate this effort to the key component of electronic species' life history. ${ }^{20}$ Many conditions influence parenting efforts. These include genetic relationship, biological sex, and parental age and condition, as well as family size, and offspring characteristics. Mating opportunities and paternity uncertainty are factors known to affect parental engagement, as are external factors of the environment, including ecological conditions. ${ }^{21}$ These factors interact in the process of developing parental functioning. The parents try to guarantee the parental function. This means that the parents did their best to meet the child's needs. ${ }^{22}$ Like a mother who cannot give her baby enough breast milk and uses energy and strategy to get it. She goes to the breast milk bank and asks the other mother who has extra or enough breast milk to share with her, and these shows the depict effort.

Parental responsibility refers to the responsibilities and author- 
ity of parents, their legal rights and duties, as well as their power over children and the child's things. ${ }^{23}$ There is one important element related to responsibility that needs to be decided. In the functional parental context, the decision to take care of the child's needs comes with responsibility. The WHO notes that there are components that parents should provide for their child. These includes good household, adequate complementary feeding, breastfeeding and infection control to support the stunted growth and development. ${ }^{24}$ Parents are responsible for providing for children's needs, for example, a safe and protective environment, sufficient food, ${ }^{25}$ cleanliness, physical care, and financial support. ${ }^{26,27}$

Partnership between parents ideally involve both parents participating actively in making decisions and putting them into action. The parents should perceive each other as having equal strength and ability. Both should be contributing as well as benefitting from each other's actions or care and they should be able to share roles. ${ }^{28}$ Each parent has a big stake in what the other one does with the child. Parenting as partners supports parental responsibility, facilitating healthy marriages and development of relationship skills. In addition, co-parenting helps mothers understand the importance of a father's involvement with their children. Partnerships also develop between parents and others; effective partnering supports people who are involved in raising a child, including grandparents, caretakers, teachers, coaches, health providers, and the community in general. ${ }^{29}$ In addition, the partnership is not limited to parenthood itself. It's about working with other health care providers like nurses and pediatricians and the people of the region (brothers and sisters, neighbors). It is working together as a team and supports each other. Partnership is built by the participation of each actor to promote good outcome for the child.

Caring can be defined as feeling or showing concern or kindness to others. ${ }^{30}$ Caring for the child is full of meaning and requires sensitivity. Acts of caring, in addition to performing their direct functions, also symbolize attachment itself. ${ }^{31}$ The way parents show love cannot be separated from the condition of relationship between mother and father. Because it is reflected in each other. When a relationship or marriage is in favorable and happy state, it will promote caring for the child. Caring cannot be separated from compassion, and compassion for parents and children shows that positive affection in the parent-child relationship is also a more forgiving view of one's own parenting efforts. ${ }^{32}$ Parent will not be sad when they cannot achieve the goal of parenting within a time frame. There will always be an opportunity to struggle in better way. They do not blame each other, they do better and better again in order to meet the goal of parenting.

Parents provided cognitive stimulation activities and games appropriate to the children's developmental phase, ${ }^{33,34}$ enabled socialization with friends and arrange a healthy daily life for children. ${ }^{29}$ In addition, parents should develop different strategies to encourage a child to eat healthier food. ${ }^{3}$ In a cross sectional study done in (country), parents' role as nutritionists was clear from the results of extracted factor analysis on the constructs related to parents teaching children about nutrition and shared activities involving food. ${ }^{24}$

Communication includes the components of communicating with the child through verbalization ${ }^{35}$ and parents acting as active listeners. ${ }^{26}$ A previous study reported that adults act in such a way that they communicate their own mindset to children. ${ }^{33}$ This implies that there is a need adjusted communication between parents and children according to the children's age. Communication provides necessary resources, such as reinforcement to motivate children by encouraging positive changes in health behavior and to respect what children have learned. ${ }^{36}$

\section{Model case}

Model cases provide examples of how to apply a concept and illustrate all the defining attributes of the concept. A model case may be situated at different points in the analysis; it may appear first, could develop along with the explication of the attributes, or may appear after the attributes have been tentatively identified. ${ }^{10}$ Below is an example of a case illustrating the use of the concept of parental functioning:

Mr. and Mrs. Nusantara are parents of a two-year-old stunted child, Srikandi. Understanding the condition of their child, they do not blame themselves for not taking care of the child. They search for information on stunting on the Internet and in other literature. Also, they seek a pediatrician for consultation about their child's growth and development. They love their child very much as evidenced by hugging their child whenever they wake up and before going to bed. They have a regular mealtime routine with proper portions or "empat sehat lima sempurna" (carbohydrates, protein, vegetables, fruit plus milk) and they encourage Srikandi to eat more if the meals are healthy, delicious and good for her. Moreover, they give her vitamins, bathe her, provide quiet playtimes and have a bedtime routine. They make an extra effort to have their home child-proofed to be sure it is safe as their daughter is exploring the world. They take their daughter to visit the pediatrician for routine examinations to monitor her growth and development and for immunizations. They also bring her to a tukang pijat for traditional massage to ensure the growth of their child. Mr. and Mrs. Nusantara treat Srikandi well and they are listen actively to their child.

\section{Borderline case}

A borderline case contains many, but not all attributes of the concept under study. ${ }^{9}$ This means, the attributes are reported within the context, but only some. This borderline case helps to reflect on the attributes of the concept of interest. The illustration of the borderline case describe as below:

Mr. and Mrs. Nusantara understand that their only daughter is stunted. Both parents agreed to take care of Srikandi as much as they can. They provide learning opportunities to their child through social activities as she grew. Her parents love her unconditionally, care for her through loving attachment. She can do anything that she desires. Sometimes, Srikandi eats whatever she wants and plays outside without asking for permission from her parents. Mr. and Mrs. Nusantara communicate same way the school age communicate and actively listen to their child. Mrs. Nusantara routinely bring Srikandi to Posyandu, provide adequate food, hygiene, medical care and fulfill all of her needs.

The attributes are available, which fulfills knowledge, partnership, caring, providing and communicating, but lack of teaching. It is mentioned as sometimes, Srikandi eats whatever she wants and plays outside without her parents' permission.

\section{Related case}

Related cases are similar to the model case, and have some attributes of parental functioning, but do not include all the defining attributes. ${ }^{9}$ Parenting functioning and caretaking functioning are two related concepts; they sound similar, but actually differ. To give the reader a deeper understanding about parenting functioning, below is an example of a related case: 
Dewi cares for her nephew, Sierra because the mother is working overseas. She loves her nephew very much. She shows her care through provision of food, comfort home to take a rest, accompany her to do routine medical checkup to the doctor, and creating safe living environment. Dewi communicates kindly to her nephew.

Reviewing the above example, it sounds similar between concept of parenting functioning and family functioning. Although these concepts are similar, they differ because it does not include the parenting functioning attributes with additional attributes of partnership and teaching.

\section{Contrary case}

Contrary cases offer clear examples that prove the concept does not match the reality. ${ }^{9}$ This depicts that the narrative has no concept of parenting functioning. To give an example about the contrary case, literature review online using neglected malnourish children as the key word was carried out. Here is the example of contrary case:

A two-year-old Lauren Wade was emaciated, dirty and riddled with head lice when she died in March 2015. She was skinny, dirty and unkempt at the time. She also has a sodden nappy, bald patches and thousands of head lice. She lived with both of her parents in a flat that was littered with rubbish, leftover food, dirty plates and clothes. There were also hundreds of insects and flies. Lauren's mother and her partner regarded themselves as the toddler's parents. They told others that they did their best as parents. ${ }^{37}$

The story above is clearly a case of dysfunctional parenting. The story identified no attributes of knowledge, partnership, caring, providing, teaching and communicating.

\section{Invented case}

Invented cases are imaginary; they contain ideas outside real experience. These may involve an extraordinary or imagined context. ${ }^{9}$ Below is an example of an invented case to illustrate the concept of parental functioning:

Entering the $21^{\text {st }}$ century, technology rules life. Robots can be great parents and are well-versed in caring for a child by providing food and learning activities appropriate to the child's age. The robot parent hugs the child before bed and plays lullabies. They also communicate with the child and listen actively to the child. If the robot discovers something amiss with the child, the robot's system will help in solving the problem.

Analyzing the narrative above, attributes such as knowledge, partnership, caring, providing, teaching and communicating were reported and gains the concept of parenting functioning. Robots can do the "parenting" and time-saver in parenting. The real parents will be helpful by the existence of the robots in such a way that they can do other jobs. This case represents parenting functioning; however it is not with parent. Therefore, it called by invented case.

\section{Illegitimate case}

In an illegitimate case, the concept is used incorrectly or out of context, in a way that distorts its meaning. It may have one or two essential attributes, but many are not applicable at all. ${ }^{9}$ The following narrative is an example of in illegitimate case of parenting functioning:
Mr. Arjuna and his family live together with his parents (extended family). He loves his only child, five-year-old Kunti. He sets boundaries for his daughter and is a harsh disciplinarian. He felt that he was a good parent and doing an adequate job. By contrast, he thinks that his mother is not a good role model and does not discipline Kunti effectively. Thus he does not always agree with how his mother raises Kunti. When he comes home, Kunti runs to her father then hugs Arjuna and says, "Hello daddy...". Arjuna tells his mother, "See? Kunti loves and respects me. That's called good parenting."

At a glance, the narrative above appears to depict good parenting, but it is not actually the meaning of parental functioning. Good parenting requires a loving relationship between the parent and the child. This relationship is achieved when the child feels her father cares about her, while the father shapes the child's behavior with positive reinforcement and modeling ideal behaviors. On the contrary, harsh discipline creates fear and negative reinforcement may produce maladaptive behaviors instead.

\section{Antecedents and consequences}

The next stage in a concept analysis is identifying antecedents and consequences. These two aspects of a case can reveal important insights about the social contexts in which the concept is generally used, although some authors may skip one or both. ${ }^{9}$ The antecedents are conditions that emerged before the attributes and consequences are conditions that follow from the attributes. Antecedents are events or incidents that must occur prior to the occurrence of the phenomenon to be analyzed. ${ }^{9}$ The antecedents of parental functioning are relationships, children's characteristics, careful parental observation and vicariously sharing in their child's experience. The relationship is between two or more people in whom at least one person plays the role of a parent and at least one person plays the role of a child, regardless of age. ${ }^{7}$ In this case, the condition of a stunted child is set as antecedents where parenting functioning is meaningful for the children with stunting. The antecedents cases starts when parents observed their child is short and the height is less than other children in the same age. Below is the example of antecedents cases of parenting functioning:

Mr. and Mrs. Nusantara gave birth to a baby girl. As the time goes by, they observed that their children look different. Their baby girl has short in stature compared with other children in the same age. Srikandi is two-year-old, her height is $80 \mathrm{~cm}$ and weight 8.5 $\mathrm{kg}$, while Shinta is two years old, her height is $84.5 \mathrm{~cm}$ and weight $11.8 \mathrm{~kg}$ (this is appropriate as the WHO chart growth). The data show that Srikandi and Shinta are the same age, but has different height and weight. The pediatric nurse in Posyandu said that their child has been classified as a stunted child.

Consequences are incidents that occur as a result of the occurrence of the concept or as the outcomes of the concept. They are a direct result of the concept. ${ }^{9}$ The consequences of parenting functioning on children with stunting include parents' impact on children's diets. ${ }^{2}$ The stunted child does not meet standards of wellbeing, which include the increase in height and weight in accordance with the WHO Child Growth Standards. Below is the example of consequences cases:

Mr. and Mrs. Nusantara provided healthy food, shelter, hygiene, medical care, financial support, and love to Srikandi. Understanding her condition as Stunted child, they did extra effort to fulfill her needs. As a result, they could see that Srikandi has increased in height and weight. Now she is twelve years old, her height is $148 \mathrm{~cm}$ and her weight is $38.7 \mathrm{~kg}$. This number is within the normal range as mentioned in WHO Growth Standard. 


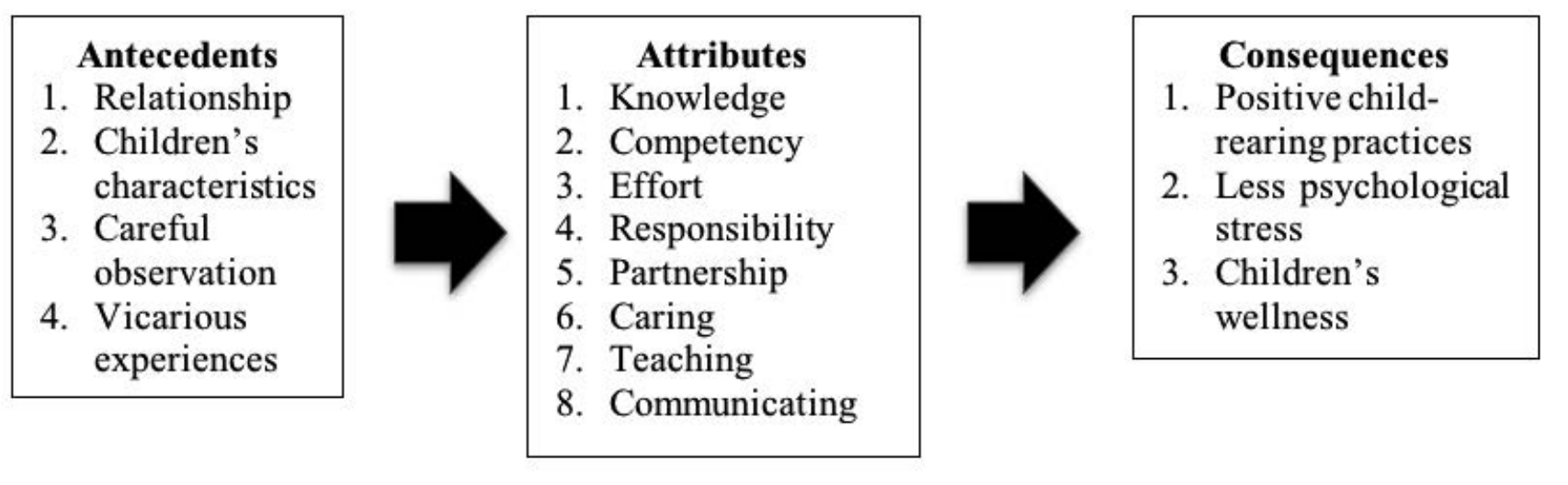

Figure 1. Antecedents, attributes, and consequences of parenting functioning.

\section{Empirical referent}

The final step in concept analysis is to measure the defining attributes as they occur in real-life cases. Empirical referents are actual phenomena the instrument organizes into categories; because they can be measured, they demonstrate that the concept describes reality. The referents relate directly to the defining attributes, not to the entire concept itself. This allows researchers to recognize or measure the defining characteristics or attributes that comprise the overall concept. ${ }^{9}$ Empirical referents of parenting functioning are the following: knowledge and behavior on parenting, fulfillment needs, and parenting interactions with children.

To identify the component, an instrument may be useful. Keys to Interactive Parenting Scale (KIPS) shows how parents grow and meet the parenting functioning. This measurement consists of twelve items associated to parenting. These relations build together with the families members in order to promote parent-child relationship, learning, and support confidence. The component of parenting behavior assessment describes as bellow: i) Building relationship: response to sensitivity, emotional support, interaction of physical condition, imply in children's activity, and sharing in child's agenda; ii) Learning promotion: experience in communication, reasonable expectations, adapts strategies to child, and limits and consequences; iii) Espouse to confidence: supportive guidance, encouragement, promotes exploration and curiosity.

At this point, the assessment can be carried out through observation and discussion. The needs of child have been mentioned above in the component of responsibility. In order to meet fulfillment needs, parents need to determine if the things they are providing are suitable for their child or not. The interaction created by parents is essential to the child growth and development. PICOLLO derived from Parenting Interaction with Children: Checklist of Observations Linked to Outcomes' born as an observational measure of developmental parenting, which seems very useful both for assessment and intervention. The assessment under the PICCOLO guideline needs 10 minutes observation focusing on practices that include affection, responsiveness, encouragement and teaching. It is assumed that this measure supports a continuous improvement in the quality of parents and children in early childhood as a pre- dictor of future success in school and life. It gathers information about positive adult-child interactions that support children's development through talking and play.

This concept analysis has so far been limited to research literature, most of which is generated from non-nursing discipline. Psychology science is the most chosen as source of the literature. Since this concept is quite new, the empirical referents of the concept may change. This analysis of concept parenting functioning offers a unique set of attributes, antecedents, consequences and empirical referents. The summary is shown in Figure 1. Parenting functioning should become variable assess by nurse to understand the correlation between parenting functioning, child and growth development. Further analysis is needed to understand that parenting functioning has an impact on reducing prevalence of stunting through prevention and/or stunting management.

\section{Conclusions}

Nurses need to understand how parenting works in order to strengthen their role. The functioning of parents means an action of complex activities related to the upbringing of children and all related responsibilities. These actions are influencing the child's outcome. ${ }^{15}$ Nurses promote how parenting functioning can promote better condition of stunting case in children. Evaluation on parenting functioning becomes a measure its function as expected. On a broader level, nurses ought to take more actions in policy making. This is a good chance to break off communication between nurses and stakeholders. Empowering the parents with stunted children is an uprising agenda, which discuss the issue related to stunting and its relation on parenting functioning. Further, nurses are also encouraged to participate in research about parenting functioning, especially its relevance with stunting. Few studies discuss about the association and correlation between parenting functioning and stunting. Clarifying the concept of parenting functioning will first makes it function well in research strive in nursing discipline area. Advance collaborations with other health care profession are needed to strengthen the position of evidence findings through research. 
Correspondence: Anggie Pradana Putri, International Nursing PhD Program, National Taipei University of Nursing and Health Sciences, No. 365 Mingde Road, Beitou Distric Taipei City 112, Taiwan. Tel. +886.2.2822710- Fax: +886.2.2820-6729.

E-mail: anggie.pputri@gmail.com

Key words: Parenting functioning; stunting; concept analysis.

Contributions: APP conceived of the study, refered the concept analysis reserach model, did the data collection and analysis also drafted the article. JRR had role in the supervision of the study and advised on the drafts of the study and approved the final manuscript.

Conflict of interests: There is no conflict of interest within the study.

Funding: The authors received no support for the research, authorship, and publication of this article.

Acknowledgement: The authors thank to International Nursing $\mathrm{PhD}$ Program, National Taipei University of Nursing and Health Sciences, Taiwan for the support during the study.

Conference presentation: Part of this study was presented at the $1^{\text {st }}$ International Nursing and Health Sciences Symposium, November $13^{\text {th }}$ to $15^{\text {th }} 2020$, Brawijaya University, Malang, Indonesia.

Received for publication: 17 January 2021.

Accepted for publication: 24 March 2021

(C) Copyright: the Author(s), 2021

Licensee PAGEPress, Italy

Journal of Public Health Research 2021;10:2160

doi:10.4081/jphr.2021.2160

This work is licensed under a Creative Commons Attribution

NonCommercial 4.0 License (CC BY-NC 4.0).

\section{References}

1. UNICEF. The state of the world's children 2019: East Asia and Pacific. New York: UNICEF; 2018.

2. Vaughn AE, Ward DS, Fisher JO, et al. Fundamental constructs in food parenting practices: a content map to guide future research. Nutr Rev 2016;74:98-117.

3. World Health Organization. Global nutrition target 2025: stunting policy brief. Geneva: World Heatlh Organization; 2014.

4. Torlesse H, Cronin AA, Sebayang SK, Nandy R. Determinants of stunting in Indonesian children: Evidence from cross-sectional survey indicate a prominent role for the water, sanitation and hygiene sector in stunting reduction. BMC Public Health 2016;16:669-80.

5. World Bank Group [Internet]. Indonesia: Aiming high: Indonesia's ambition to reduce stunting 2018 [cited 2019 Jan 24]. Available from: https://openknowledge.worldbank. org/handle/10986/30151\#: :text=It $\% 20$ examines $\% 20$ the $\% 20$ government's\%20plans,fashion \%20in \%20communities\%20ac ross $\% 20$ Indonesia

6. Seay A, Freysteinson WM, McFarlane J. Positive parenting. Nurs Forum 2014;49:200-8.

7. Meleis AI. Theoretical nursing development and progress. Philladelphia: Lippincot Williams \& Wilkins; 2018.

8. Walker LO, Avant KC. Strategies for theory construction nursing. New Jersey: Pearson Prentice Hall; 2014.

9. Virasiri S, Yunibhand J, Chaiyawat W. Parenting: what are the critical atributes? J Med Assoc Thailand 2011;94:1109-16.

10. Cambridge Dictionary [Internet]. Parenting. Cambridge: Cambridge University Press; 2019. Available from: https: //dictionary.cambridge.org/dictionary/english/parenting

11. Ordway MR, Sadler LS, Dixon J, et al. Parental reflective functioning. J Clin Nurs 2014;23:3490-500.

12. Luyten P, Mayes LC, Nijssens L, et al. The parental reflective functioning questionnaire: Development and preliminary validation. PLoS One 2017;12:e0176218.

13. Canavera K, Johnson LM, Harman J. Beyond parenting: the responsibility of multidisciplinary health care providers in early intervention policy guide. Am J Bioeth 2018;18:58-60.

14. Jordan A, Eccleston C, Crombez G. Parental functioning in the context of adolescent chronic pain: a review of previously used measures. J Pediatr Psychol 2008;33:640-59.

15. Merriam-Webster [Internet]. Knowledge. Springfield: Merriam-Webster Inc.; 2019. [cited 2019 Jan 24]. Available from: https://www.merriam-webster.com/dictionary/knowledge

16. World Health Organization. The healthy growth project. Geneva: World Health Organization; 2015.

17. Barlett JD, Guzman L, Ramos-Olazagasti MA. 5 things to know about parents' knowledge of parenting and early childhood development [Internet]. Bethesda: Child Trends; 2018 [cited 2019 Jan 24]. Available from: https://www.childtrends.org/child-trends-5/5-things-to-knowabout-parents-knowledge-of-parenting-and-early-childhooddevelopment

18. Cambridge [Internet]. Competency Cambridge: Cambridge University Press; 2019. [cited 2019 Jan 24]. Available from: https://dictionary.cambridge.org/dictionary/english/competency

19. Centranum group [Internet]. How to develop competency models. Auckland: Centranum Group; 2019. [cited 2019 Jan 24]. Available from: https://www.centranum.com/wp-content/uploads/dlm_uploads/2019/09/How-to-developCompetency-models.pdf

20. Collins [Internet]. Effort. UK: Collins; 2019 [cited 2019 Jan 24]. Available from: https://www.collinsdictionary.com/dictionary/english/effort

21. Meehan C. Parenting effort. In: A. Bolin, P. Whelehan, Editors. The International Encyclopedia of Human Sexuality. Hoboken: Wiley; 2015. p. 861-1042.

22. Baca TC, Figuerdo AJ, Ellis BJ. An evolutionary analysis of variation in parental effort: determinants and assessment. Parent Sci Pract 2012;12:4-104.

23. Gingerbread [Internet]. Parental responsibility. London: Gingerbread; 2017. Available from: https://www. gingerbread.org.uk/wp-content/uploads/2017/08/Parental-responsibility.pdf

24. Marshall S, Golley R, Hendrie G. Expanding the understanding of how parenting influences the dietary intake and weight status of children: A cross sectional study. Nutr Diet 2011;68:127-33.

25. Masse LC, Watts AW. Stimulating innovations in the measurement of parenting constructs. Child Obes 2013;9:S5-13.

26. Meyiwa, T. Constructing an alternative family unit: Families living with HIV/AIDS redefine African traditional parenting patterns. Soc Dynam 2011;37:165-177.

27. Berry JW. Conceptual approaches to acculturation. In: KM Chun, P Balls Organista, G Marín, Editors. Acculturation: Advances in theory, measurement, and applied research. Washington DC: American Psychological Association; 2003. p. 17-37.

28. Abed MG. Challenges to the concept "partnership with par- 
ents" in a special needs education. J Educ Psychol 2014;7:111.

29. Center for Parenting and Education [Internet]. Parenting tip: Work together as a team. Center for Parenting; 2019 [cited 2019 Jan 24]. Available from: https://centerforparentingeducation.org/parentscorners/2018/02/parenting-tip-work-togetherteam/

30. Merriam-Webster [Internet]. Caring. Springfield : MerriamWebster Incorporated; 2019 [cited 2019 Jan 24]. Available from: https:/www.merriam-webster.com/dictionary/caring

31. Bantley ME, Wasser HM, Creed-Kanashiro HM. Responsive feeding and child undernutrition in low-and middle-income countries. J Nutr 2011;141:502-7.

32. Duncan LG, Coatsworth J, Greenberg MT. A model of mindful parenting: Implications for parent-child relationships and prevention research. Clin Child Fam Psychol Rev 2009;12:25570 .
33. LeCuyer M, Elizabeth A. Maternal sensitivity and responsiveness, limit setting style and relationship history in the transition to toddlerhood. Issues Compr Pediatr Nurs 2000;23:11739.

34. Gavin LE, Black MM, Minor S, et al. Young, disadvantaged fathers' involvement with their infants: An ecological perspective. J Adolesc Health 2002;31:266-76.

35. Haimovits K, Dweck CS. The origins of children's growth and fixed mindsets: New research and a new proposal. Child Dev 2017;88:1-9.

36. Wolde T, Belachew T. Chronic undernutrition (stunting) is detrimental to academic performance among primary schools of adolescent children: a randomized cross sectional survey in Southern Ethiopia. BMC Res Notes 2019;12:142-58.

37. BBC. Couple neglected two-year-old who died of malnutrition. Glasgow: BBC; 2018. 